\title{
Meta-analysis: Anticholinergics, but not $\beta$-agonists, Reduce Severe Exacerbations and Respiratory Mortality in COPD
}

\author{
Shelley R. Salpeter, MD, 1,2 Nicholas S. Buckley, ${ }^{3}$ Edwin E. Salpeter, PhD \\ 'Department of Medicine, Stanford University School of Medicine, Stanford, CA, USA; ${ }^{2}$ Department of Medicine, Santa Clara Valley \\ Medical Center, San Jose, CA, USA; International Baccalaureate Program, Sequoia High School, Redwood City, CA, USA; ${ }^{4}$ Center for \\ Radiophysics and Space Research, Cornell University, Ithaca, NY, USA.
}

\begin{abstract}
BACKGROUND: Anticholinergics and $\beta 2$-agonists have generally been considered equivalent choices for bronchodilation in chronic obstructive pulmonary disease (COPD).
\end{abstract}

OBJECTIVE: To assess the safety and efficacy of anticholinergics and $\beta 2$-agonists in COPD.

DESIGN: We comprehensively searched electronic databases from 1966 to December 2005, clinical trial websites, and references from selected reviews. We included randomized controlled trials of at least 3 months duration that evaluated anticholinergic or $\beta 2$-agonist use compared with placebo or each other in patients with COPD.

MEASUREMENTS: We evaluated the relative risk (RR) of exacerbations requiring withdrawal from the trial, severe exacerbations requiring hospitalization, and deaths attributed to a lower respiratory event.

RESULTS: Pooled results from 22 trials with 15,276 participants found that anticholinergic use significantly reduced severe exacerbations (RR 0.67, confidence interval [CI] 0.53 to 0.86 ) and respiratory deaths (RR 0.27, CI 0.09 to 0.81 ) compared with placebo. $\beta 2$-Agonist use did not affect severe exacerbations (RR 1.08, CI 0.61 to 1.95 ) but resulted in a significantly increased rate of respiratory deaths (RR 2.47, CI 1.12 to 5.45) compared with placebo. There was a 2-fold increased risk for severe exacerbations associated with $\beta 2$-agonists compared with anticholinergics (RR 1.95, CI 1.39 to 2.93). The addition of $\beta 2$ agonist to anticholinergic use did not improve any clinical outcomes.

CONCLUSION: Inhaled anticholinergics significantly reduced severe exacerbations and respiratory deaths in patients with COPD, while $\beta 2$-agonists were associated with an increased risk for respiratory deaths. This suggests that anticholinergics should be the bronchodilator of choice in patients with COPD, and $\beta 2$-agonists may be associated with worsening of disease control.

KEY WORDS: chronic obstructive pulmonary disease; COPD; adrenergic $\beta$-agonists; cholinergic antagonists; muscarinic antagonists; meta-analysis; clinical outcomes; mortality.

DOI: $10.1111 / \mathrm{j} .1525-1497.2006 .00507 . \mathrm{x}$

J GEN INTERN MED 2006; 21:1011-1019.

$\mathrm{C}$ hronic obstructive pulmonary disease (COPD) is characterized by partially reversible chronic airflow obstruction caused by an abnormal inflammatory reaction in the airways and lung parenchyma to inhaled toxins, most notably cigarette smoke. ${ }^{1,2}$ The clinical course is marked by a slow progressive decline in lung function, considered to be the stable phase of

None of the authors have had any relationships with a manufacturer of a $\beta 2$-agonist or anticholinergic agent at any time.

Address correspondence and requests for reprints to Dr. Salpeter: 751 S. Bascom Ave, San Jose, CA 95128 (e-mail: salpeter@stanford.edu). the disease, with episodic acute exacerbations presenting as an increase in dyspnea, cough, and/or sputum production. ${ }^{1,3}$ Exacerbations requiring hospitalization are associated with $3 \%$ to $4 \%$ short-term mortality. ${ }^{3}$ Half of those patients hospitalized will be readmitted at least once over the next 6 months. ${ }^{3}$ Chronic obstructive pulmonary disease is the fourth leading cause of death in the United States. ${ }^{4}$

Treatment with inhaled corticosteroids has been shown to reduce local inflammatory cells and systemic markers such as C-reactive protein, improve respiratory symptoms, reduce COPD exacerbations, and slow the progression of lung function decline. ${ }^{5-9}$ Anticholinergic bronchodilators inhibit bronchoconstriction as well as mucus secretion, and have been shown to improve symptoms and reduce exacerbations without producing tolerance to their effects over time. ${ }^{10-16}$ Inhaled anticholinergics are poorly absorbed from the gastrointestinal tract and lung, so that systemic adverse effects are rare. ${ }^{10,17} \beta 2$-Agonists are bronchodilators that relax bronchial smooth muscle and are effective in the short-term relief of COPD symptoms. ${ }^{18}$ However, long-term use may be associated with tolerance to their effects. ${ }^{11,14}$

We are gradually accumulating evidence concerning the increased risk $\beta 2$-agonists have for adverse respiratory and cardiovascular events in patients with asthma and COPD, and are now questioning whether long-acting $\beta 2$-agonists such as salmeterol and formoterol should be taken off the market. ${ }^{19-31}$ Pooled data from 19 randomized controlled trials showed that long-acting $\beta 2$-agonists increase hospitalizations for asthma (odds ratio [OR] 2.6, confidence interval [CI] 1.6 to 4.3), lifethreatening asthma exacerbations requiring intubation and ventilation (OR 1.8, CI 1.1 to 2.9) and asthma-related deaths (OR 3.5, CI, 1.3 to 9.3) compared with placebo. ${ }^{32}$

The 2 types of bronchodilators, anticholinergics and $\beta 2$ agonists, have generally been considered to be equivalent choices for use in patients with COPD. ${ }^{1,33,34}$ Despite the fact that anticholinergics have been shown to have equal or superior efficacy compared with $\beta 2$-agonists, ${ }^{15,35-39}$ surveys have shown that prescriptions for $\beta 2$-agonists in COPD are 10 times more common than anticholinergics in the United States and 2 times more common in the United Kingdom and Europe. ${ }^{40-42}$ The objective of this meta-analysis is to compare the effects of $\beta 2$-agonists and anticholinergics on exacerbations requiring

Manuscript received December 23, 2005

Initial editorial decision March 3, 2006

Final acceptance April 4, 2006 
withdrawal from the trial, severe exacerbations requiring hospitalization, and respiratory deaths in patients with COPD.

\section{MATERIALS AND METHODS}

\section{Search Strategy}

We performed a comprehensive search of MEDLINE, EMBASE, and Cochrane databases to identify randomized controlled trials on 32 -agonist or anticholinergic use in patients with COPD, published between 1966 and December 2005. The search was performed using the terms bronchodilator, sympathomimetic, adrenergic $\beta$-agonist, anticholinergic, cholinergic antagonist, muscarinic antagonist, albuterol, salbutamol, bitolterol, isoetharine, metaproterenol, salmeterol, terbutaline, fenoterol, formoterol, procaterol, isoproterenol, reproterol, eformoterol, bambuterol, ipratropium, tiotropium, or oxitropium and obstructive lung disease, obstructive airway disease, obstructive pulmonary disease, or COPD. Trials were not excluded on the basis of language. The search was augmented by scanning relevant files from the U.S. Food and Drug Administration (FDA) website and references of identified reviews.

\section{Study Selection}

Trials were included if they were randomized controlled trials of $\beta 2$-agonists or anticholinergics compared with placebo or each other, were of at least 3 months duration and reported at least one COPD exacerbation requiring withdrawal from the trial or hospitalization, or any respiratory death. A minimum duration of 3 months was chosen to allow for the development of adverse events. Trials that did not report any included event were excluded from the primary analysis, but were evaluated separately in order to estimate absolute risk differences.

\section{Assessment of Validity}

Two reviewers assessed the methodological quality of each trial according to the following factors: (1) Was the randomization procedure adequate and was allocation concealment described?, (2) Were patients and providers blind to the interventions?, (3) Were dropouts and withdrawals reported?, and (4) Was analysis performed by intention-to-treat? Each of these quality domains was scored on a 3-point scale. The quality assessment was used for a sensitivity analysis. ${ }^{43,44}$

\section{Data Extraction and Synthesis}

Two reviewers extracted data from the selected articles, reconciling differences by consensus. In addition, attempts were made to contact the investigators to obtain additional information concerning exacerbations and deaths. The proportion of patients with COPD exacerbations, severe exacerbations, and respiratory deaths from each trial was pooled using the fixed-effects model, expressed as relative risk (RR) with corresponding 95\% confidence intervals. ${ }^{45}$ COPD exacerbations were those that required withdrawal from the study or hospitalization. Severe exacerbations were those requiring hospitalization. A respiratory death was defined as a death thought to be due to a lower respiratory tract event, such as a COPD exacerbation, pneumonia, or respiratory failure. Deaths thought to be due to a cardiorespiratory cause were included, if they were thought to be related to the underlying COPD. To test for interstudy heterogeneity, the chi-square value was calculated for the hypothesis of homogeneity, with statistical significant set at $\alpha=0.1$. The fixed-effects model was chosen as minimal heterogeneity was noted in the analyses.

Results were reported separately for placebo-controlled trials of anticholinergics and $\beta 2$-agonists, and for trials comparing $\beta 2$-agonists to anticholinergics. The analysis was performed using Cochrane Review Manager 4.2 (Cochrane Library Software, Oxford, UK). Only trials that reported at least 1 event were used in the estimation of RR. If more than 1 event occurred in the same patient, only the first event was counted. In a separate analysis, those trials that reported no respiratory deaths were evaluated in order to estimate an absolute risk difference. The number needed to treat (NNT) to prevent an event, and the number needed to harm (NNH) to cause an event, were calculated.

\section{Role of the Funding Source}

The funding for this analysis came from salary support for Dr. Salpeter. The institution had no role in the design, conduct, or reporting of the study. The investigators all had complete access to the data, and no sponsorship from the institution or the pharmaceutical industry was provided to conduct this analysis.

\section{RESULTS}

\section{Search Results}

Figure 1 shows the results of the search for articles. The MEDLINE search identified approximately 5,000 articles, of which 84 were potentially relevant trials of bronchodilator use in COPD. After scanning references from selected articles and the FDA website, an additional 4 trials were identified. The EMBASE and Cochrane databases provided no additional trials. Of these 88 trials, 22 met the inclusion criteria. ${ }^{12,13,46-65}$

Trials were excluded for the following reasons: 37 trials were of less than 3 months duration, 9 trials did not provide adequate information on exacerbations or respiratory deaths, 2 trials did not compare the 2 types of bronchodilators with placebo or each other, 4 trials were not randomized, 2 trials provided data for asthma and COPD combined, and 12 trials provided data on participants from other trials.

\section{Trial Characteristics}

The analysis included 22 trials, with a total of 15,276 participants followed for 25,460 patient-years (Table 1). The mean trial duration was 20 months (range 3 to 60 months), with a mean study size of 694 participants (62 to 3,923). The mean (SD) age of participants at baseline was 59.9 (7.7) years in the anticholinergic group, 63.5 (1.0) in the $\beta 2$-agonist group and 59.6 (7.4) years in the placebo group. The dropout rate was $18.5 \%$ in the anticholinergic group, $19.0 \%$ in the $\beta 2$-agonist group and $24.8 \%$ in the placebo group. From the available data, concomitant corticosteroids were used in $58.3 \%$ of the anticholinergic group, $56.5 \%$ of the $\beta 2$-agonist group and $57.4 \%$ of the placebo group. $\beta 2$-agonists used in the trials were albuterol, metaproterenol, formoterol, and salmeterol. Anticholinergic agents studied were ipratropium and tiotropium. 


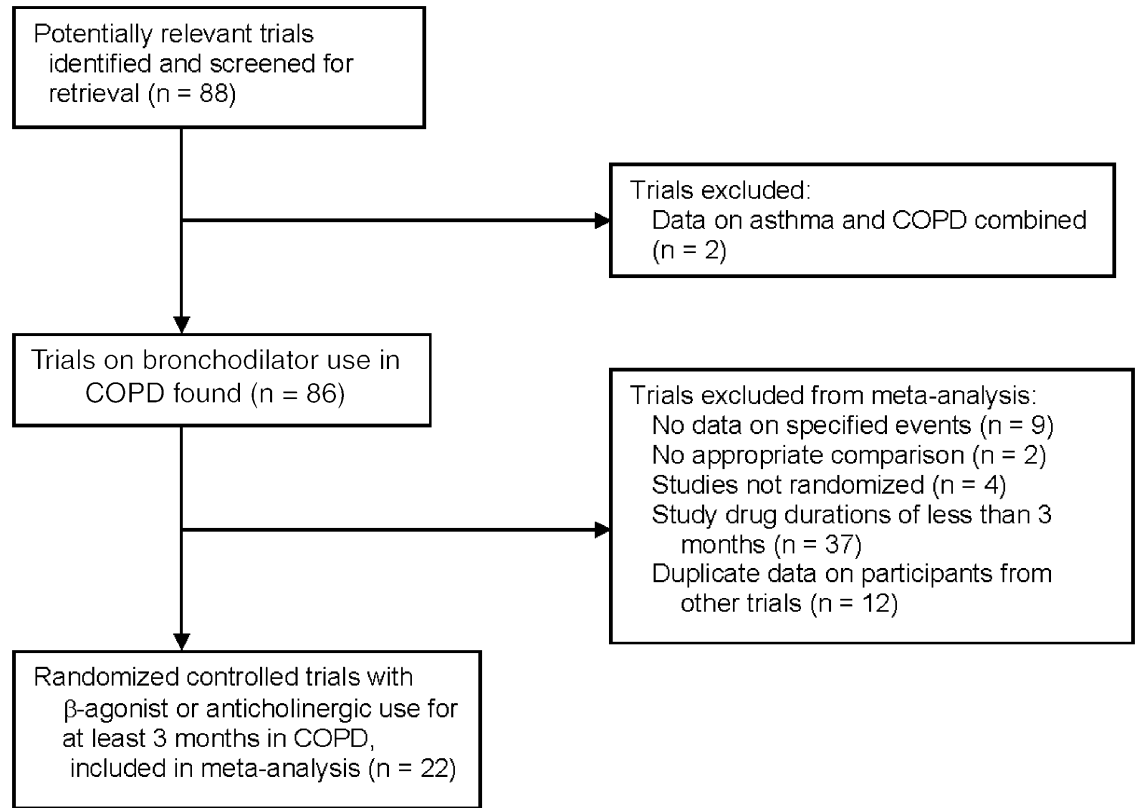

FIGURE 1. Flow chart of trials search.

\section{Methodological Quality of Included Studies}

All trials were randomized, double blind trials that performed analysis according to intention-to-treat and adequately described withdrawals. Thirteen trials described the method of randomization or allocation concealment, while 9 did not. No trial received the lowest quality score on any domain, so no sensitivity analysis was performed.

\section{Quantitative Data Synthesis}

Anticholinergics Compared with Placebo. Seven trials compared inhaled anticholinergics with placebo (Fig. 2). Anticholinergics reduced the risk of a COPD exacerbation requiring withdrawal from the trial by $40 \%$ (RR 0.60 , CI 0.48 to 0.75 ) and a severe exacerbation requiring hospitalization by $33 \%$ (RR 0.67, CI 0.53 to 0.86). The absolute risk reduction for severe exacerbations was approximately 4 cases per 100 patient-years of treatment compared with placebo, with a NNT of 25 .

The Lung Health Study ${ }^{47}$ provided data on hospitalization for lower respiratory morbidity but not COPD exacerbations, so these were not included in the analysis. If data on lower respiratory morbidity were included as COPD exacerbations, the RR for hospitalization would be 0.75 (CI 0.61 to 0.93 ).

There were 2 reported respiratory deaths out of 4,036 participants in the anticholinergic group and 12 respiratory deaths out of 3,845 participants in the placebo group, with a reduction in risk of $73 \%$ (RR 0.27 , CI 0.09 to 0.81 ). In order to assess absolute rates for respiratory deaths we included those trials that reported no deaths, thus adding to the denominator. The absolute risk reduction for respiratory deaths with anticholinergics was $0.36 \%$ per year (NNT of 278).

B2-Agonists Compared with Placebo. There were 13 trials that compared $\beta 2$-agonist use with placebo (Fig. 3). All of the trials except for one ${ }^{55}$ evaluated the long-acting $\beta 2$-agonists salmeterol and formoterol. Of note, all trials allowed for as-need- ed $\beta 2$-agonist use in both the treatment and placebo groups, so in effect were comparing regular $\beta 2$-agonist use with as-needed use. Concomitant inhaled corticosteroids were used in $57 \%$ of participants.

The risk of withdrawal from the trial for COPD exacerbation was reduced by $19 \%$ (RR 0.81 , CI 0.68 to 0.95 ), without a significant effect on hospitalization (RR 1.08, CI, 0.61 to 1.95). However, $\beta 2$-agonist use was associated with a significant increase in respiratory deaths (RR 2.47, CI 1.12 to 5.45) compared with placebo, with 21 deaths out of 1,320 participants in the $\beta 2$-agonist group and 8 deaths out of 1,084 participants in the placebo group. When trials without respiratory deaths were included in the analysis, thus adding to the denominator, the absolute risk increase with $\beta 2$-agonists is $0.76 \%$ per year (NNH of 131).

One trial ${ }^{66}$ provided $60 \%$ of the weight for respiratory deaths, with data provided from unpublished information and a published erratum. ${ }^{67}$ This trial also studied combined treatment with budesonide plus formoterol and budesonide treatment alone, and reported 5 deaths out of 254 patients in the combined treatment group and 6 deaths out of 257 patients in the budesonide group (RR 0.84 , CI, 0.26 to 2.73, $P=.78$ ).

B2-Agonists Compared with Anticholinergics. Seven trials directly compared $\beta 2$-agonists with anticholinergics (Fig. 4). Three of the trials did not allow for any open-label $\beta 2$-agonist use in either of the treatment groups (Table 1). Compared with anticholinergics, $\beta 2$-agonists resulted in increased rates of exacerbations requiring withdrawal from the trial (RR 2.02, CI 1.39 to 2.93 ) as well as severe exacerbations requiring hospitalization (RR 1.95, CI 1.06 to 3.59). Only 2 trials reported on respiratory deaths, with a nonsignificant trend toward increased respiratory mortality associated with $\beta 2$-agonists compared with anticholinergics (RR 6.91, CI 0.85 to 55.97, $P=0.07)$. 


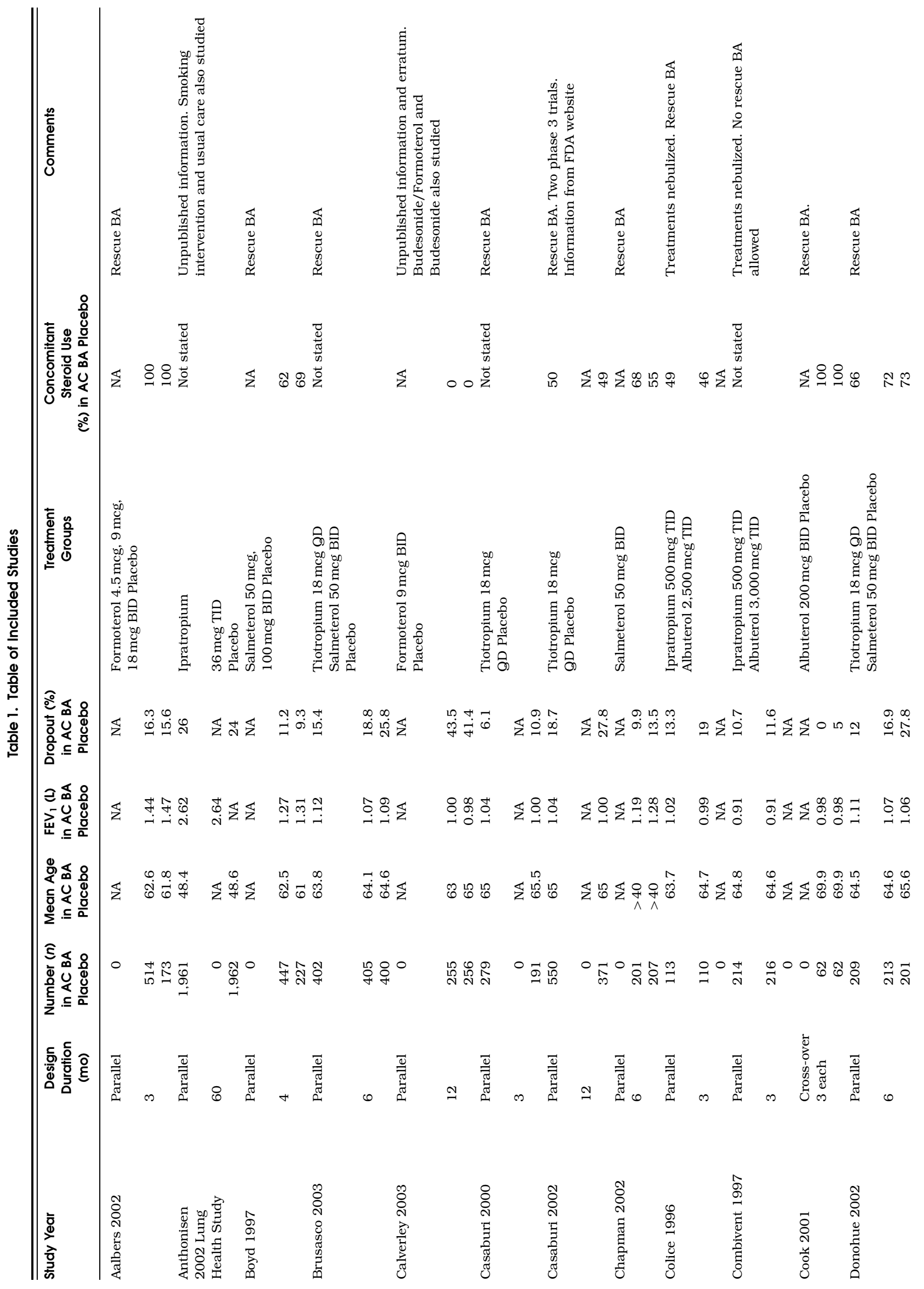




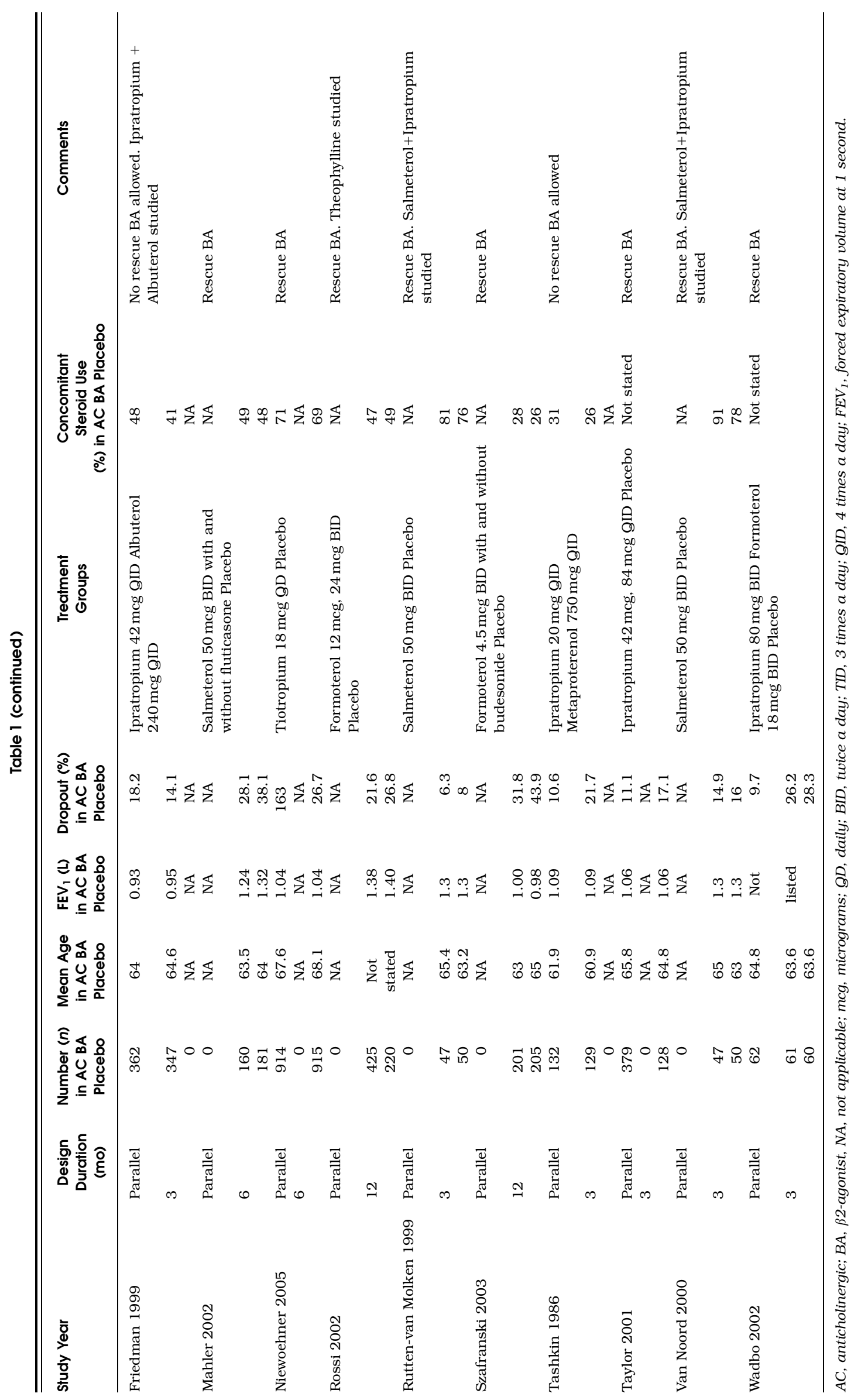




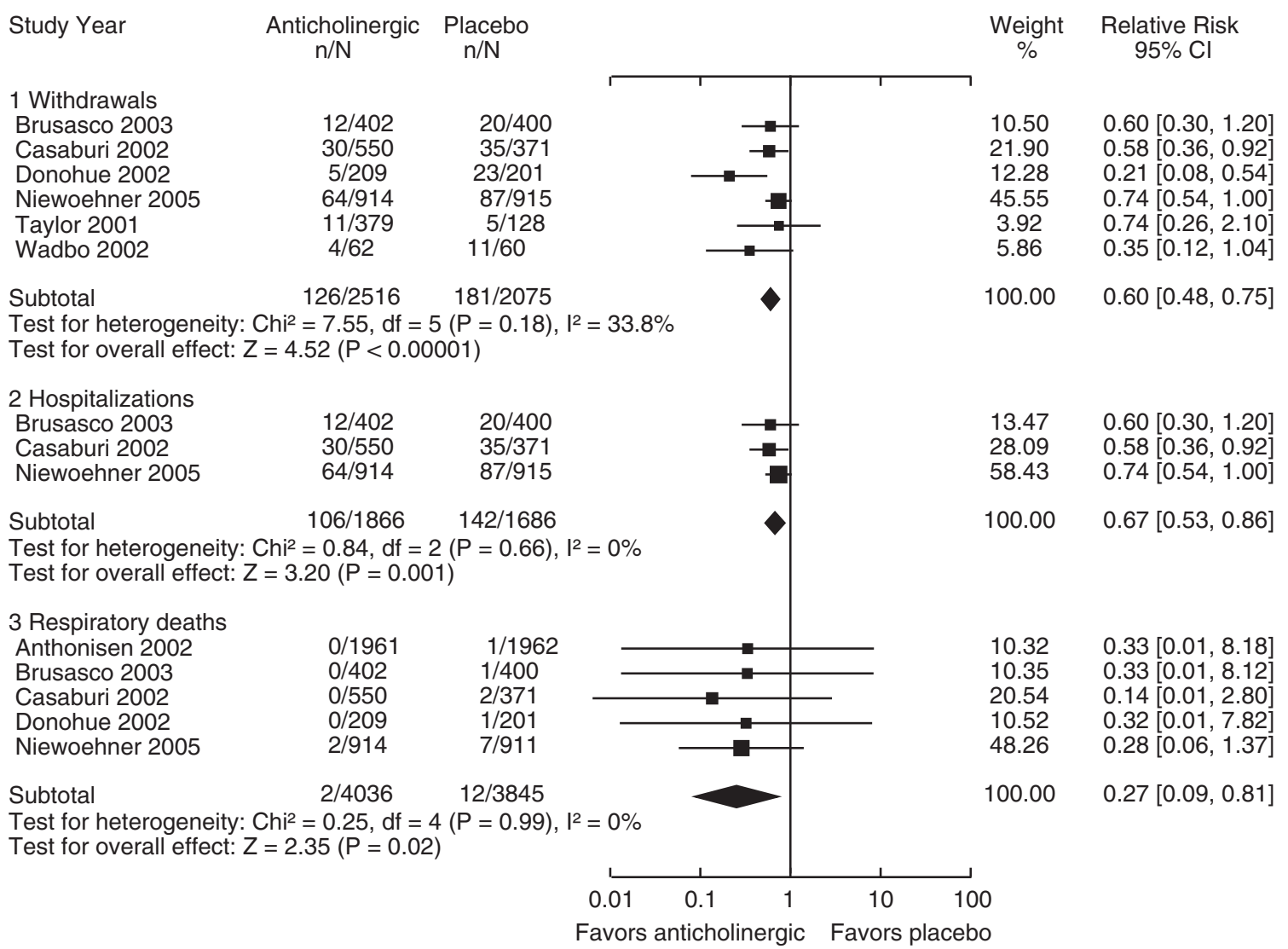

FIGURE 2. Effect of anticholinergics compared with placebo on chronic obstructive pulmonary disease withdrawals, hospitalizations, and respiratory deaths (relative risk).

Four trials compared anticholinergics alone to combination treatment with anticholinergic and $\beta 2$-agonist. ${ }^{52,54,55,57}$ Anticholinergic use alone was not associated with a significant difference in severe exacerbations (RR 0.83 , CI 0.25 to 3.83 ) or deaths (RR 0.35, CI 0.04 to 3.3) compared with combination treatment.

Analysis of Interstudy Variance and Publication Bias. No evidence of significant heterogeneity was noted in any of the analyses, $P>$.3. Funnel plots of effect size versus standard error found no evidence for publication bias in the analysis.

\section{DISCUSSION}

Pooled results from 22 randomized trials of patients with COPD show that anticholinergics reduced severe exacerbations by $33 \%$ and respiratory deaths by $73 \%$ compared with placebo, while $\beta 2$-agonists resulted in a 2 -fold increase in respiratory deaths. The absolute risk reduction for respiratory deaths associated with anticholinergics is $0.36 \%$ per year (NNT of 278) and the absolute risk increase associated with $\beta 2$-agonists is $0.76 \%$ per year (NNH of 131). The addition of a $\beta 2$ agonist to an anticholinergic agent did not improve clinical outcomes. These results suggest that anticholinergics should be the bronchodilator of choice in COPD.

In order to put the risks of $\beta 2$-agonists into perspective we must also understand the benefits. Pooled data from randomized trials have shown that $\beta 2$-agonists are effective broncho- dilators in patients with COPD, with some trials showing an improvement in symptom scores. ${ }^{18,68}$ This meta-analysis indicates that $\beta 2$-agonists can reduce withdrawals for symptomatic exacerbations by almost $20 \%$. However, this improvement in symptoms may occur at the same time as a worsening of disease control, manifested by an increase in respiratory mortality. Tolerance to the bronchodilator effect of $\beta 2$-agonists has been documented in patients with COPD over time, with a significant decline in strength of bronchodilation after 3 months of treatment compared with the first dose. ${ }^{11-13,15,16,52,54}$ Evidence of tolerance to the bronchoprotective effect of $\beta 2$-agonist use in COPD has also been demonstrated, with an increase in bronchial hyperresponsiveness seen with regular treatment. ${ }^{14}$

This meta-analysis shows that the anticholinergics, ipratropium and the newer long-acting tiotropium, reduced severe exacerbations and respiratory mortality compared with placebo. Unfortunately, in the United States only 5\% of all prescriptions for COPD are anticholinergics. ${ }^{40}$ Tiotropium has been shown to prevent the decline in trough FEV1 values that are seen with placebo use over the course of 1 year. ${ }^{50,51,69}$ This finding suggests that anticholinergics, like inhaled corticosteroids, may slow the progressive decline in lung function that is seen in patients with COPD. Currently, a 4-year trial of tiotropium is under way to test this hypothesis. ${ }^{17}$ Two trials have compared tiotropium with ipratropium; pooled results show that tiotropium is associated with fewer severe exacerbations than ipratropium (RR 0.56, CI 0.36 to 0.89) ${ }^{69,70}$ A cost- 


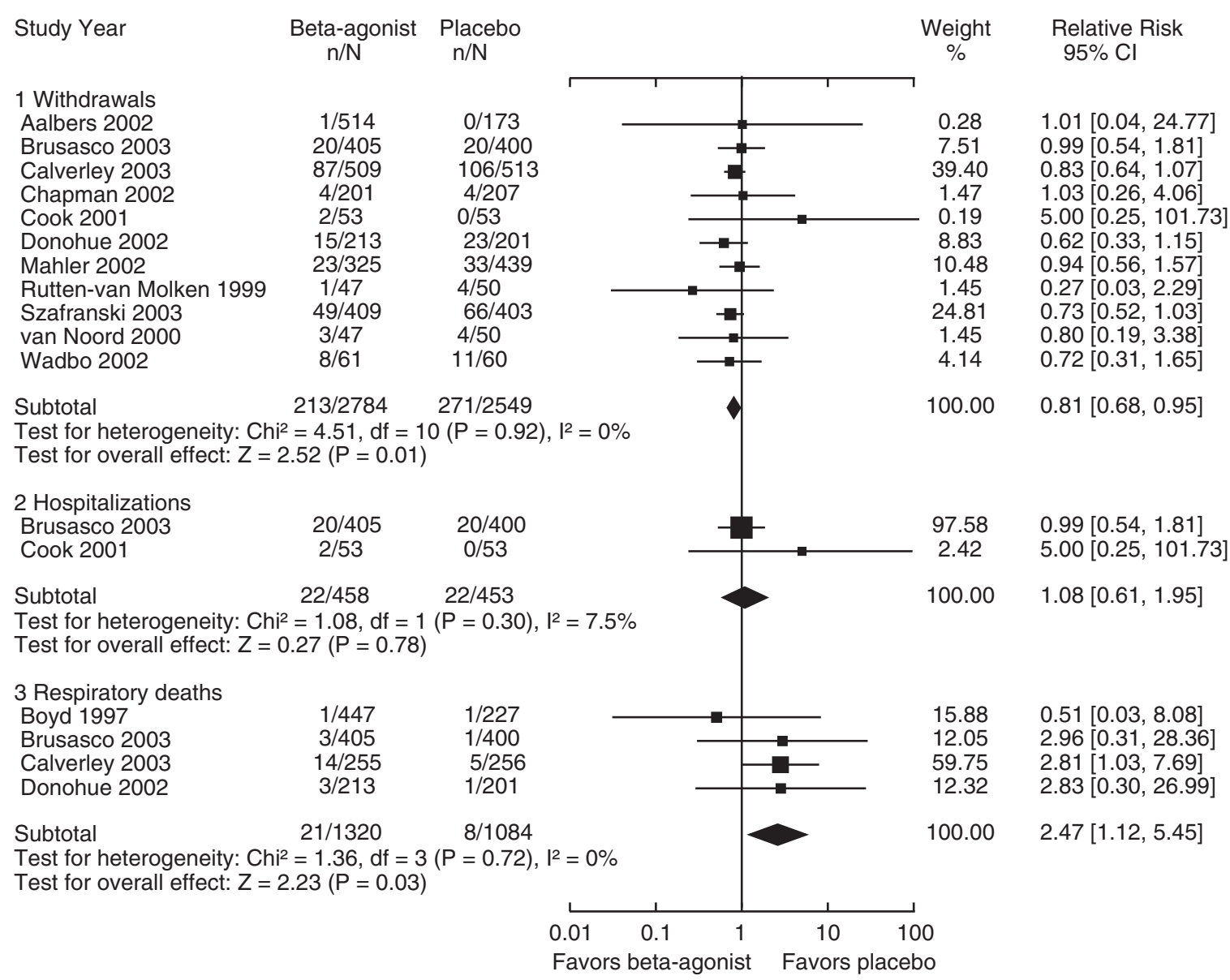

FIGURE 3. Effect of $\beta 2$-agonists compared with placebo on chronic obstructive pulmonary disease withdrawals, hospitalizations, and respiratory deaths (relative risk).

effectiveness analysis found that costs associated with tiotropium are slightly higher than with ipratropium, but that the reduction in hospitalization is thought to be cost-effective. ${ }^{71}$

Current guidelines recommend that an inhaled bronchodilator (anticholinergic or $\beta 2$-agonist) be used in the treatment of stable COPD, and if symptoms persist or there are frequent exacerbations the addition of an inhaled corticosteroid should be considered. ${ }^{33}$ In this meta-analysis approximately one-half of the patients treated with $\beta 2$-agonists had concomitant inhaled corticosteroid use. Three trials ${ }^{49,58,62}$ provided data with and without inhaled corticosteroids, but only 1 provided information on severe exacerbations or respiratory deaths, ${ }^{66}$ so subgroup analysis on the effect of concomitant inhaled corticosteroids could not be done.

This analysis has several limitations. Standard meta-analytic results can be uncertain when the numbers of events per study are small, as is the case with deaths. Some of the analyses in this study provided pooled data from only 2 trials, so may not provide meaningful results. There was not enough information available to assess the potential protective effect of concomitant inhaled corticosteroids on the adverse effects of $\beta 2$-agonists, or the difference in results for long-acting and short-acting $\beta 2$-agonists. The search revealed 9 trials that were excluded because no severe exacerbations or deaths were reported. It is difficult to tell if events occurred but were not reported. Other trials did not provide cause of death, so could not be included in the analysis of respiratory deaths. The accurate assessment of respiratory deaths was further hindered by the difficulty in ascertaining the true cause of death. For example, it is possible that the increase in respiratory deaths seen with 32 -agonists may be due in part to an increase in cardiovascular risk. ${ }^{30}$ Finally, it is unfortunate that no true placebo-controlled trials of $\beta 2$-agonist use in COPD have been published. Despite these limitations, we believe that this metaanalysis provides valuable information on the comparative effects of anticholinergics and $\beta 2$-agonists on clinical outcomes in COPD.

In summary, both anticholinergics and $\beta 2$-agonists may be effective bronchodilators and improve symptoms in patients with COPD. Anticholinergics reduced severe exacerbations and respiratory deaths in patients with COPD. However, $\beta 2$-agonists had no effect on severe exacerbations and resulted in an increased rate of respiratory deaths, possibly owing to a reduction in disease control. Concomitant corticosteroids were used in over one-half of patients treated with $\beta 2$-agonists, but it is not clear if this provided some protection against the adverse effects. The results of this meta-analysis suggest that anticholinergics should be the bronchodilator of choice in patients with COPD. The long-term safety of $\beta 2$-agonists in patients with COPD should be addressed. 


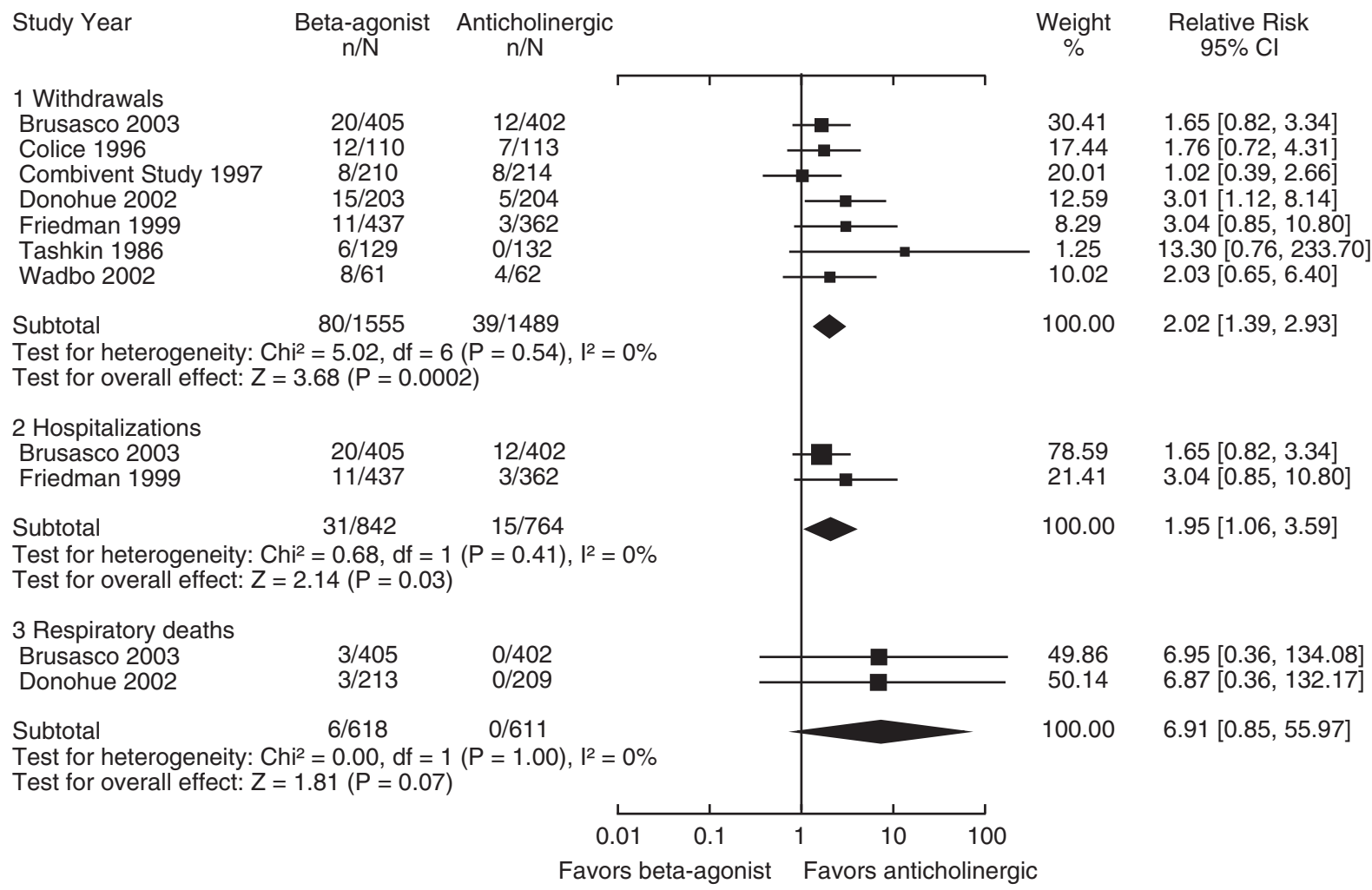

FIGURE 4. Effect of $\beta 2$-agonists compared with anticholinergics on chronic obstructive pulmonary disease withdrawals, hospitalizations, and respiratory deaths (relative risk).

We would like to thank Christopher Stave for coordinating the trials search.

\section{REFERENCES}

1. Celli BR, MacNee W. Standards for the diagnosis and treatment of patients with COPD: a summary of the ATS/ERS position paper. Eur Respir J. 2004;23:932-46.

2. Agusti AG. COPD, a multicomponent disease: implications for management. Respir Med. 2005;99:670-82.

3. McCrory DC, Brown CD, Gelfand SE, Bach PB. Management of acute exacerbations of COPD A summary and appraisal of published evidence. Chest. 2001;119:1190-209.

4. U.S. Department of Health and Human Services. COPD data fact sheet. NIH publication No. 03-5229. 2003.

5. Gan WQ, Man SF, Sin DD. Effects of inhaled corticosteroids on sputum cell counts in stable chronic obstructive pulmonary disease: a systematic review and a meta-analysis. BMC Pulm Med. 2005;5:3.

6. Alsaeedi A, Sin DD, McAlister FA. The effects of inhaled corticosteroids in chronic obstructive pulmonary disease: a systematic review of randomized placebo-controlled trials. Am J Med. 2002;113:59-65.

7. van Grunsven PM, van Schayck CP, Derenne JP, et al. Long term effects of inhaled corticosteroids in chronic obstructive pulmonary disease: a meta-analysis. Thorax. 1999;54:7-14.

8. Sutherland ER, Allmers H, Ayas NT, Venn AJ, Martin RJ. Inhaled corticosteroids reduce the progression of airflow limitation in chronic obstructive pulmonary disease: a meta-analysis. Thorax. 2003;58:937-41.

9. Sin DD, Lacy P, York E, Man SF. Effects of fluticasone on systemic markers of inflammation in chronic obstructive pulmonary disease. Am J Respir Crit Care Med. 2004;170:760-5.

10. Barnes PJ. The role of anticholinergics in chronic obstructive pulmonary disease. Am J Med. 2004; 117(Suppl 12A):24S-32S.

11. Donohue JF, Menjoge S, Kesten S. Tolerance to bronchodilating effects of salmeterol in COPD. Respir Med. 2003;97:1014-20.

12. Brusasco V, Hodder R, Miravitlles M, Korducki L, Towse L, Kesten S. Health outcomes following treatment for six months with once daily tiotropium compared with twice daily salmeterol in patients with COPD. Thorax. 2003;58:399-404.

13. Tashkin DP, Ashutosh K, Bleecker ER, et al. Comparison of the anticholinergic bronchodilator ipratropium bromide with metaproterenol in chronic obstructive pulmonary disease. A 90-day multi-center study. Am J Med. 1986;81:81-90.

14. van Schayck CP, Graafsma SJ, Visch MB, Dompeling E, van Weel C, van Herwaarden CL. Increased bronchial hyperresponsiveness after inhaling salbutamol during 1 year is not caused by subsensitization to salbutamol. J Allergy Clin Immunol. 1990;86:793-800.

15. Rennard SI, Serby CW, Ghafouri M, Johnson PA, Friedman M. Extended therapy with ipratropium is associated with improved lung function in patients with COPD. A retrospective analysis of data from seven clinical trials. Chest. 1996;110:62-70.

16. Ashutosh $\mathbf{K}$, Lang $\mathbf{H}$. Comparison between long-term treatment of chronic bronchitic airway obstruction with ipratropium bromide and metaproterenol. Ann Allergy. 1984:53:401-6.

17. Tashkin DP. Is a long-acting inhaled bronchodilator the first agent to use in stable chronic obstructive pulmonary disease? Curr Opin Pulm Med. 2005; 11:121-8.

18. Sestini P, Renzoni E, Robinson S, Poole P, Ram FS. Short-acting beta 2 agonists for stable chronic obstructive pulmonary disease. Cochrane Database Syst Rev. 2002(4): CD001495.

19. U.S. Food and Drug Administration. Labeling changes for drug products that contain salmeterol. FDA Talk Paper. 2003: T03-62.

20. U.S. Food and Drug Administration. Study of asthma-drug halted. FDA Talk Paper 2003: T03-06.

21. U.S. Food and Drug Administration. Division of Pulmonary and Allergy Drug Products Medical Officer Review. Salmeterol. 2005.

22. Salpeter SR, Ormiston TM, Salpeter EE. Meta-analysis: respiratory tolerance to regular beta2-agonist use in patients with asthma. Ann Intern Med. 2004;140:802-13.

23. Kraan J, Koeter GH, vd Mark TW, Sluiter HJ, de Vries K. Changes in bronchial hyperreactivity induced by 4 weeks of treatment with antiasthmatic drugs in patients with allergic asthma: a comparison between budesonide and terbutaline. J Allergy Clin Immunol. 1985;76: 628-36. 
24. Sears MR, Taylor DR, Print CG, et al. Regular inhaled beta-agonist treatment in bronchial asthma. Lancet. 1990;336:1391-6.

25. Lipworth BJ. Risks versus benefits of inhaled beta 2-agonists in the management of asthma. Drug Safety. 1992;7:54-70.

26. Sovani MP, Whale CI, Tattersfield A. A benefit-risk assessment of inhaled long-acting beta2-agonists in the management of obstructive pulmonary disease. Drug Safety. 2004;27:689-715.

27. Suissa S, Blais L, Ernst P. Patterns of increasing beta-agonist use and the risk of fatal or near-fatal asthma. Eur Respir J. 1994;7:1602-9.

28. Au DH, Curtis JR, Psaty BM. Risk of myocardial ischaemia and betaadrenoceptor agonists. Ann Med. 2001;33:287-90.

29. Salpeter SR. Cardiovascular safety of beta(2)-adrenoceptor agonist use in patients with obstructive airway disease: a systematic review. Drugs Aging. 2004;21:405-14.

30. Salpeter SR, Ormiston TM, Salpeter EE. Cardiovascular effects of beta-agonists in patients with asthma and COPD: a meta-analysis. Chest. 2004; 125:2309-21.

31. U.S. Food and Drug Administration Advisory Committee. Serevent, Advair, Foradil withdrawals to be considered by Advisory Committee. 2005.

32. Salpeter SR, Buckley NS, Ormiston TM, Salpeter EE. Long-acting beta-agonists increase severe asthma exacerbations and asthma-related deaths: meta-analysis of randomized controlled trials. Ann Intern Med. 2006; in press.

33. National Collaborating Centre for Chronic Conditions. Chronic obstructive pulmonary disease National clinical guideline on management of chronic obstructive pulmonary disease in adults in primary and secondary care. Thorax. 2004;59(Suppl 1):1-232.

34. Cooper CB, Tashkin DP. Recent developments in inhaled therapy in stable chronic obstructive pulmonary disease. BMJ. 2005;330:640-4.

35. Sin DD, McAlister FA, Man SF, Anthonisen NR. Contemporary management of chronic obstructive pulmonary disease: scientific review. JAMA. 2003;290:2301-12.

36. Tashkin DP, Cooper CB. The role of long-acting bronchodilators in the management of stable COPD. Chest. 2004;125:249-59.

37. Pakes GE, Brogden RN, Heel RC, Speight TM, Avery GS. Ipratropium bromide: a review of its pharmacological properties and therapeutic efficacy in asthma and chronic bronchitis. Drugs. 1980;20:237-66.

38. Karpel JP. Bronchodilator responses to anticholinergic and beta-adrenergic agents in acute and stable COPD. Chest. 1991;99:871-6.

39. McCrory DC, Brown CD. Inhaled short-acting beta2-agonists versus ipratropium for acute exacerbations of chronic obstructive pulmonary disease. Cochrane Database Syst Rev. 2001(2): CD002984.

40. Ramsey SD. Suboptimal medical therapy in COPD: exploring the causes and consequences. Chest. 2000;117(2 Suppl):33S-7S.

41. Rudolf M. The reality of drug use in COPD: the European perspective. Chest. 2000;117(2 Suppl):29S-32S.

42. Roche N, Lepage T, Bourcereau J, Terrioux P. Guidelines versus clinical practice in the treatment of chronic obstructive pulmonary disease. Eur Respir J. 2001;18:903-8.

43. Jadad AR, Moore A, Carroll D, Jenkinson C, Reynolds DJ, Gavaghan DJ. Assessing the quality or reports of randomized clinical trials. Control Clin Trials. 1996;17:1-12.

44. Schultz KF, Chalmers I, Hayes RG, Altman DG. Empirical evidence of bias: dimensions of methodological quality associated with estimates of treatment effects in controlled trials. JAMA. 1995;273:408-12.

45. Mantel N, Haenszel W. Statistical aspects of the analysis of data from retrospective studies of disease. J Natl Cancer Inst. 1959;22:719-48.

46. Aalbers R, Ayres J, Backer V, et al. Formoterol in patients with chronic obstructive pulmonary disease: a randomized, controlled, 3-month trial. Eur Respir J. 2002; 19:936-43.

47. Anthonisen NR, Connett JE, Enright PL, Manfreda J. Hospitalizations and mortality in the lung health study. Am J Respir Crit Care Med. 2002;166:333-9.

48. Boyd G. Salmeterol xinafoate in asthmatic patients under consideration for maintenance oral corticosteroid therapy. UK study group. Eur Respir J. 1995;8:1494-8.

49. Calverley PM, Boonsawat W, Cseke Z, Zhong N, Peterson S, Olsson H. Maintenance therapy with budesonide and formoterol in chronic obstructive pulmonary disease. Eur Respir J. 2003;22:912-9.

50. Casaburi R, Briggs DD Jr, Donohue JF, Serby CW, Menjoge SS, Witek TJ Jr. The spirometric efficacy of once-daily dosing with tiotropium in stable COPD: a 13-week multicenter trial The US tiotropium study group. Chest. 2000;118:1294-302.

51. Casaburi R, Mahler DA, Jones PW, et al. A long-term evaluation of once-daily inhaled tiotropium in chronic obstructive pulmonary disease. Eur Respir J. 2002; 19:217-24.

52. Chapman KR, Arvidsson P, Chuchalin AG, et al. The addition of salmeterol 50 microg bid to anticholinergic treatment in patients with COPD: a randomized, placebo controlled trial. Chronic obstructive pulmonary disease. Can Respir J. 2002;9:178-85.

53. Colice GL. Nebulized bronchodilators for outpatient management of stable chronic obstructive pulmonary disease. Am J Med. 1996;100:11S$18 \mathrm{~S}$

54. Combivent Inhalation Solution Study Group. Routine nebulized ipratropium and albuterol together are better than either alone in COPD. The COMBIVENT inhalation solution study group. Chest. 1997;112:1514-21

55. Cook D, Guyatt G, Wong E, et al. Regular versus as-needed short-acting inhaled beta-agonist therapy for chronic obstructive pulmonary disease. Am J Respir Crit Care Med. 2001;163:85-90.

56. Donohue JF, van Noord JA, Bateman ED, et al. A 6-month, placebo-controlled study comparing lung function and health status changes in COPD patients treated with tiotropium or salmeterol. Chest. 2002;122:47-55.

57. Friedman M, Serby CW, Menjoge SS, Wilson JD, Hilleman DE, Witek TJ Jr. Pharmacoeconomic evaluation of a combination of ipratropium plus albuterol compared with ipratropium alone and albuterol alone in COPD. Chest. 1999;115:635-41.

58. Mahler DA, Wire P, Horstman D, et al. Effectiveness of fluticasone propionate and salmeterol combination delivered via the Diskus device in the treatment of chronic obstructive pulmonary disease. Am J Respir Crit Care Med. 2002;166:1084-91.

59. Niewoehner DE, Rice $\mathbf{K}$, Cote $\mathbf{C}$, et al. Prevention of exacerbations of chronic obstructive pulmonary disease with tiotropium, a once-daily inhaled anticholinergic bronchodilator: a randomized trial. Ann Intern Med. 2005; 143:317-26.

60. Rossi A, Kristufek P, Levine BE, et al. Comparison of the efficacy, tolerability, and safety of formoterol dry powder and oral, slow-release theophylline in the treatment of COPD. Chest. 2002;121:1058-69.

61. Rutten-van Molken M, Roos B, Van Noord JA. An empirical comparison of the St George's Respiratory Questionnaire (SGRQ) and the Chronic Respiratory Disease Questionnaire (CRQ) in a clinical trial setting. Thorax. 1999;54:995-1003.

62. Szafranski W, Cukier A, Ramirez A, et al. Efficacy and safety of budesonide/formoterol in the management of chronic obstructive pulmonary disease. Eur Respir J. 2003;21:74-81.

63. Taylor J, Kotch A, Rice $\mathbf{K}$, et al. Ipratropium bromide hydrofluoroalkane inhalation aerosol is safe and effective in patients with COPD. Chest. 2001;120:1253-61.

64. van Noord JA, de Munck DR, Bantje TA, Hop WC, Akveld ML, Bommer AM. Long-term treatment of chronic obstructive pulmonary disease with salmeterol and the additive effect of ipratropium. Eur Respir J. 2000; 15:878-85

65. Wadbo M, Lofdahl CG, Larsson $\mathbf{K}$, et al. Effects of formoterol and ipratropium bromide in COPD: a 3-month placebo-controlled study. Eur Respir J. 2002;20: 1138-46.

66. Calverley P, Pauwels R, Vestbo J, et al. Combined salmeterol and fluticasone in the treatment of chronic obstructive pulmonary disease: a randomised controlled trial. Lancet. 2003;361:449-56.

67. Calverley PM, Boonsawat W, Zhong N, Peterson S, Olsson H. Author's correction: maintenance therapy with budesonide and formoterol in chronic obstructive pulmonary disease. Eur Respir J. 2003;24:1075.

68. Appleton S, Poole P, Smith B, Veale A, Bara A. Long-acting beta2-agonists for chronic obstructive pulmonary disease patients with poorly reversible airflow limitation. Cochrane Database Syst Rev. 2002(3): CD001104.

69. U.S. Food and Drug Administration. NDA 21-395 Clinical briefing document. Spiriva (Tiotropium bromide) inhalation powder for COPD. 2002.

70. Vincken W, van Noord JA, Greefhorst AP, et al. Improved health outcomes in patients with COPD during 1 yr's treatment with tiotropium. Eur Respir J. 2002; 19:209-16.

71. Oostenbrink JB, Rutten-van Molken MP, Al MJ, Van Noord JA, Vincken W. One-year cost-effectiveness of tiotropium versus ipratropium to treat chronic obstructive pulmonary disease. Eur Respir J. 2004;23:241-9. 